\title{
Importance of water objects for the sustainable development of megalopolises
}

\author{
Antonina Suzdaleva ${ }^{1, *}$, Anna Hirsch ${ }^{2}$, Catherine Mayasova ${ }^{1}$ and Anastasia Prokopova ${ }^{1}$ \\ ${ }^{1}$ Moscow State University of Civil Engineering, 129337, Yaroslavskoye Shosse 26, Moscow, Russia \\ ${ }^{2}$ Göttingen, Germany
}

\begin{abstract}
The expansion of megacities leads to the isolation of a large part of their population from the environment. The lack of contact with nature contributes to the development of ecological frustrations and deprivations, unconscious sense of discomfort, which is the cause of the development of a wide range of dangerous diseases, reduction of the birth rate and degradation of the urban population. A solution to this problem can be the organization of a network of recreation places for the urban population (resorts, created on the basis of the preserved elements of the hydrographic network). Positive perception of water objects by human consciousness is one of the main means of ecological relaxation, removal of psychological stress from constant stay in anthropogenic environment. At the same time, resorts should meet the needs of all main social groups. They should include both ecological relaxation zones and places of active recreation . Particular attention is paid to the organization of environmental education activities. Private cases of recreational use of the city's water bodies are also possible, such as attracting cave explorers to study the underground rivers. In general, resorts based on urban water bodies should become a public space, covering the entire inhabited territory of the metropolis. The system of assessing the social significance of Moscow's water bodies is developed on the basis of their comprehensive survey. Analysis of their current state takes into account general patterns of historical development of hydrographic networks of the city, and the requirements of the population to the appearance of public spaces created on water bodies of the city and to assess their social significance.
\end{abstract}

\section{Statement of the problem}

The continuous growth of the population of our planet is followed by the increase in the urbanized territories scales. The increase in the number of megalopolises and the spaces occupied by them is one of manifestations of this process. The environment in which human exists moves more and more away from the natural conditions. It generates the whole range of ecological frustrations and deprivations [1]. The dissatisfaction of the requirement for the communication with nature is the cornerstone. This psychological phenomenon is not always realized by a person. At the same time, it is one of the basic reasons of the deterioration in the urban population health. That especially concerns

*Corresponding author: suzdalevaal@yandex.ru 
neurosises, depressions, cardiovascular diseases, and that can even serve as the reason of the decrease in the birth rate in the cities [2]. The practical solution of this problem is possible on the basis of implementation of the concept of sustainable urban development. What is the most general sense of the term satisfaction of the existing needs of mankind without causing any damage to the interests of future generations? As for the considered case the development of a compromise solution between the growth of the cities and the need of creation of favorable conditions for people has to go through forming of the resort network (sites for mass rest with elements of the environment) [3]. Those have to be public spaces, easily accessible for the megalopolis population. The creation of resorts on vacant sites along the water objects is perspective. It is necessary to give them social attractiveness and to create favorable ecological conditions for the achievement of positive effect. Several state programmes have already been developed and partially implemented for this purpose earlier [4]. But classical methods of the of water objects arrangement cannot give the desirable result in the territory of the megalopolis. The solution of such a task demands an innovation creative approach [5], which main objective is not the improvement of the territory, surrounding water object, but the possibility of its use for the requirements satisfaction of people in contact with the environment elements.

\section{Materials and Methods of the research}

Our results of the comprehensive examination of state and social importance of Moscow water objects as well as the analysis of the scientific literature and the project documentation concerning the matters of their improvement acted as the material for this research.

The social importance of water objects as the factors of sustainable development of megalopolises was estimated on the following system:

1 point - a dangerous water object, perceived by the population as a threat for life or for health (possible source of infectious diseases, harmful evaporations, blood-sicking insects);

2 points - an unattractive water object which type worsens the social attractiveness of the urban area (the territory around it is not used by the inhabitants for rest);

3 points - an unequipped water object, which bank is used as a spontaneous resort (for walks, picnics);

4 points - an equipped water object with a strengthened bank, benches for rest, green plantings, but not possessing any special means for involvement of inhabitants;

5 points - an attractive water object which bank is preferred by the inhabitants prefer rather than walks in other places; the special events, causing positive emotions of visitors are mostly organized on such objects.

\section{Historical aspects of the problem}

The analysis of the historical aspects is necessary both for understanding of requirements of the population to the image of the public spaces, created on city water objects and the possible directions of development of the project on their creation.

It is possible to allocate three main periods within the history of hydrographic network of any city, as well as in its own history. During each of them the population relation to the water objects changed essentially. The factors, defining their ecological condition differ too (Table 1). 
Table 1. Periods of the development of the city hydrographic network

\begin{tabular}{|c|c|c|c|}
\hline № & $\begin{array}{c}\text { Development of } \\
\text { settlements }\end{array}$ & $\begin{array}{c}\text { Forming of ecological } \\
\text { condition of the water } \\
\text { objects }\end{array}$ & $\begin{array}{c}\text { Population relation to the } \\
\text { water objects }\end{array}$ \\
\hline 1 & Small settlement & $\begin{array}{c}\text { Self-cleaning processes } \\
\text { compensate he pollution }\end{array}$ & Vital source of water supply \\
\hline 2 & $\begin{array}{c}\text { City with the } \\
\text { considerable } \\
\text { population }\end{array}$ & $\begin{array}{c}\text { Water objects are used for the } \\
\text { sewage removal }\end{array}$ & $\begin{array}{c}\text { Places of pollution congestion, } \\
\text { source of unpleasant smells and } \\
\text { infections }\end{array}$ \\
\hline 3 & Modern megalopolis & $\begin{array}{c}\text { Complete or partial isolation } \\
\text { from the catchment basin }\end{array}$ & $\begin{array}{c}\text { Need of preserving of natural and } \\
\text { cultural and historical objects }\end{array}$ \\
\hline
\end{tabular}

The majority of the cities arose from the small settlements, located on the rivers banks. Unlike landlocked water objects water in them constantly was of high quality. They were used not only for water supply, but also for sewage removal. Natural processes of selfcleaning compensated pollution till certain moment.

Water quality began to worsen with the cities emergence. It became non-drinkable. It was not prestigious to live about the polluted rivers. Separate attempts to change such a situation were sometimes made. For example, Clean Ponds in the center of Moscow were called Nasty ponds in the 17th century, they were a part of the Rachka river, in which the drains from slaughterhouses were dumped [6]. But upon the demand of Alexander Menshikov, the favourite of the Tsar, who has purchased the site for construction of the house in this area, cleaning was carried out. However, such cases were exception of the general rule. City water objects usually turned into ditches and sewage depositaries.

The use of city hydrographic network as a part of sewer system rose long ago. Such provision was considered to be natural and necessary for creating favorable conditions of life in a city. For example, there was a network of free public toilets, during blossoming of Rome, which population exceeded 1 million people, and there was a permanent water flow through that network. Drains from them were dumped in the Tiber River. According to Roman Law, the current water ("aqua profluens") was the same general natural property as air [7]. Dropping sewage in it was as natural as the receipt in smoke air from dwellings. When the emperor Vespasian had demanded the payment for the use of the flowing sewerage, it caused indignation and heated debate in the senate. And it was Vespasian, who justify his decision with the widely known aphorism "Money does not smell".

Through many centuries the small city rivers and ponds represented a great inconvenience for inhabitants, who sought to turn their underground constructions for sewage removal or to fill them up. So, several dozens of the small rivers ceased to exist in the central part of modern Moscow. Some of them remain in the form of separate fragments. For example, ponds of Moscow Zoo are the remains of the Presnya River bed [8]. Dumping of sewage through the city rivers continued up to the end of the XIX century in developed countries. Only after the sewer systems, which are taking away sewage on special sites (fields of irrigation) were created. They have appeared in Great Britain in 1865, in France in 1872, in Germany in 1876, in Russia in 1898 [9].

Nowadays most of city inhabitants are interested in the environmental problems. Restoration of water objects and their engineering-and-ecological arrangement have turned into the activity which can have a great social effect. The remains of hydrographic networks of the megalopolises are considered to be the objects around which it is perspective to create public spaces, and the city resorts are among them. Society has forgotten that a little more than 100 years ago it supported the idea of liquidation of many city small rivers and ponds. during this time the majority of the water flows, enclosed in pipes and the filled-up reservoirs already came to the condition, which makes their restoration impossible. The 
catchment basin of city hydrographic network also changed essentially. The superficial drain which is formed on its built-up square is strongly polluted and goes to the sewerage. Therefore, the filling of many modern city ponds is carried out from the centralized water supply systems. The other way consists in the creation of local treatment facilities in which processing of the waters coming to water objects is performed. the Not restoration of once existing hydrographic networks, but creation of new artificial water systems occurs as the result.

Thus, as the short historical digression proves, the hydrographic network of the city performed several various functions, such as the source of water supply, sewage removal, creation of conditions for forming of the city resorts. Their priority changed over time. But anyway, the use of water objects in one of the directions demanded correction of others. The matter is still relevant now. So, when using water objects as the central link of a city resort, it is necessary to shift the function of accumulation and assignment of drains from them to the technical systems, which are specially created for this purpose. Ignoring of this task has already led to the fact that some of the ponds surveyed by us, created during building-up new areas as the central part of a resort turned into the objects, accumulating the polluted superficial drain and garbage, which are perceived by the population negatively. (Their social importance makes up 1-2 points).

\section{Principles and main activities}

The analysis of obtained materials allows to formulate some principles, which respect gives the chance to use water objects for the sustainable development of megalopolises successfully:

\subsection{Priority of the social importance.}

Nowadays its social importance has to be the main characteristic of a city water object (population's demand). Therefore, the methods of territories improvement around the water objects have to correspond not to the commonly accepted architectural and planning canons first of all, but the needs of the population. Not all the public spaces, surveyed by the authors, met these requirements. Only some of them could get the highest mark (5 points). For example, the Trubetskoy' Estate park in Khamovniki can be pointed out.

The implicit memory is of great importance during the determination of priorities of requirements [10]. The perception of new information is unconsciously transformed by earlier remembered facts and images thanks to it. It can be childhood memories, because of which basic change of the water object image can be perceived negatively. Movies, books and stories of elderly people can also form the implicit memory. Return to water object of the corresponding image is perceived very positively as a rule. But it is necessary to consider that the implicit memory distorts the historical realities, idealizes them. Therefore, it is necessary not to reconstruct earlier existing conditions, but to create so-called "spirit of the place", to place structures in the territory of the resort, which give it certain emotional coloring. For example, it can be the model of water-mill (fig. 1). The similar project has been developed by the authors for the Zhuzha River in the territory of park zone of the city memorial estate Kolomna, and is now developed for the ecological arrangement of the Chermyanka River. 


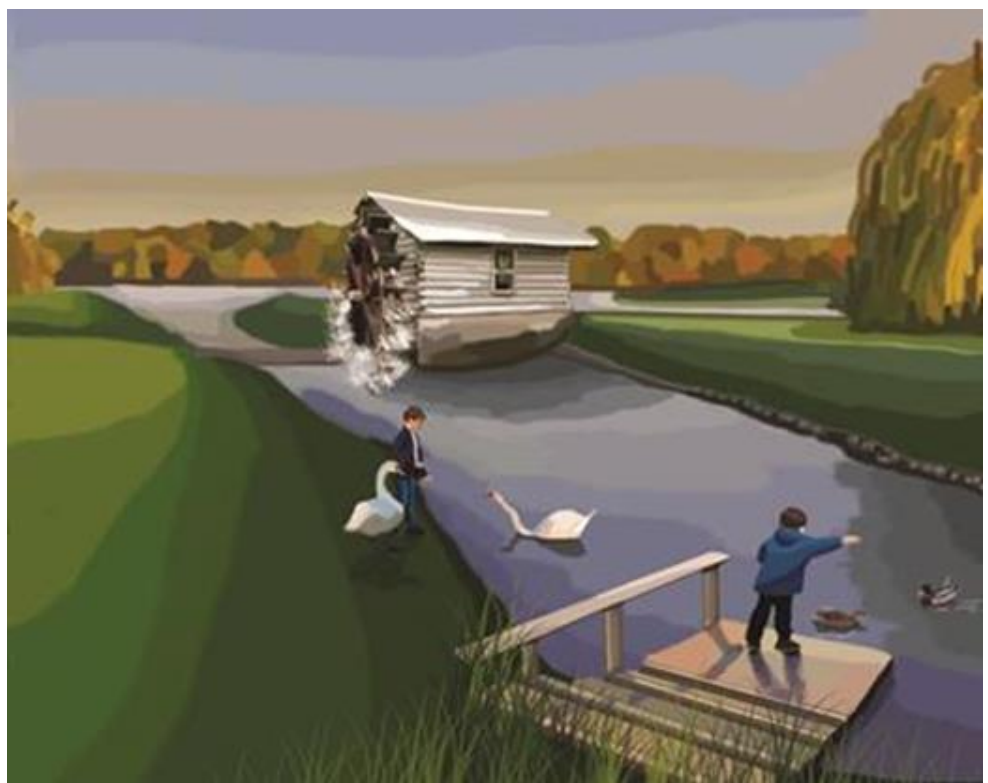

Fig. 1. The sketch of the project solution of the creation of an artificial pond in the mouth of the Zhuzha River with the water-mill model

\subsubsection{Complex use.}

The interests of various groups of society differ significantly. Young people in the majority are inclined to active holiday. People of advanced age need to have a rest, sitting down on convenient bench and overlooking the reservoir. Parents walking with small children are interested in receiving of the impressions contributing to the spiritual and intellectual development during walks. For this purpose, it is provided in the resorts:

- to involve different age groups in the work on the territory;

- to organize excursions and extracurricular activities for children and adolescents to get acquainted with the flora and fauna;

- to conduct public discussions of the ecology of the urban environment.

Simultaneous accomplishment of these requirements is possible by the creation of the permanent and temporary objects in the territory of resort, performing complex of various functions. The most perspective ways are:

- the creation of zones of ecological relaxation, the sites intended for the positive perception of elements of the environment (surface of the water and coastal vegetation) (fig. 2);

- organization of sports sites, active entertainments and attractions (whenever possible remote from the zones of ecological relaxation) (fig. 3);

- holding actions in the field of ecological education (creation of tree nurseries with information stands, display of video records of ecological subject, invitation of mobile mini-zoos).

\subsection{Close proximity.}

Ensuring the sustainable development of the megalopolis is possible only if the population will use ecologically focused public spaces. There are enough water objects in the territory of Moscow, which allow to organize network of such resorts within walking distance for 
most of people [4]. And artificial pools imitating small natural objects can be created in addition in some areas on the basis of methods of landscaping.

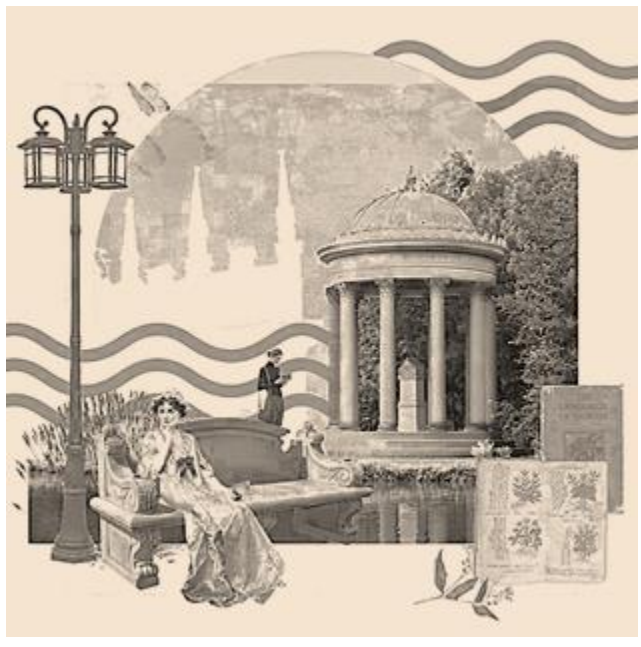

Fig. 2. Sketch of the project solution of an ecological relaxation zone

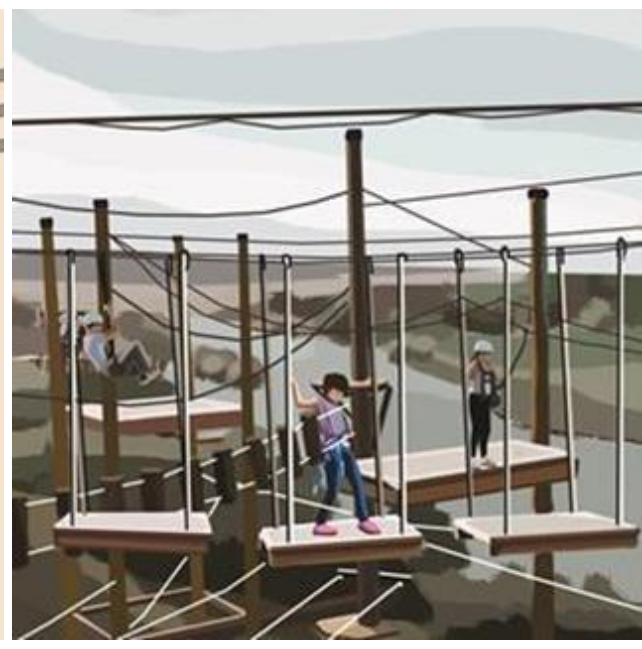

Fig. 2. Sketch of the project solution of an active holiday zone

\subsection{Providing personal and ecological safety.}

Water objects practically always represent potential threat, especially, for children. For this reason, the organization of public space on their banks has to include some measures for the accidents risk minimization. It is also necessary to consider that water objects accumulate various pollutants in themselves. If the resort is visited by great number of people the similar phenomena are inevitable. Pollution of waters in the city reservoirs can be also caused by dwelling of waterfowl [8]. The quality degradation of waters can gradually happen, and its consequences can unexpectedly be shown. It causes the need of the organization of environmental monitoring of water objects and measures on their cleaning. The hidden circulating systems of cleaning are installed on some city water objects for this purpose. They pass the large volume of water through themselves, withdrawing pollutants from it. For example, such system functions on the ponds of Moscow Zoo. In other cases in water objects the aerators, such as fountains or artificial cascades (thresholds, falls) are installed for strengthening of the self-cleaning process.

Discussing safety issues, it is necessary to pay attention to the groups of the city cave explorers exploring the underground rivers [11]. The ban of such measures in practice leads only to increase in its danger. More correct would be to organize visit of the underground rivers with experienced instructors. Similar actions are already performed in some countries. For example, in the historic center of Paris excursions in the underground medieval stone quarries located under it are organized.

\section{Gradual transformation of the depressed area on the banks of the city rivers.}

The banks of the water objects often do not meet the construction standards and requirements or their building is inexpedient economically. The condition of such territories is practically not controlled. For this reason they turn into the depressed area, the polluted 
and littered sites, reducing the social attractiveness of the urban area, located near them [12]. According to the offered classification their social importance is usually estimated as 1-2 points. However, many Moscow residents prefer to have a rest on the undeveloped sites along the banks of the small city rivers, where they can make fire or organize picnics (fig. 4). Thus, the social importance of such sites, surveyed by the authors, the Likhoborka and Skhodnya Rivers was estimated as 3 points. They can be designated as spontaneous or unorganized city resorts [13].

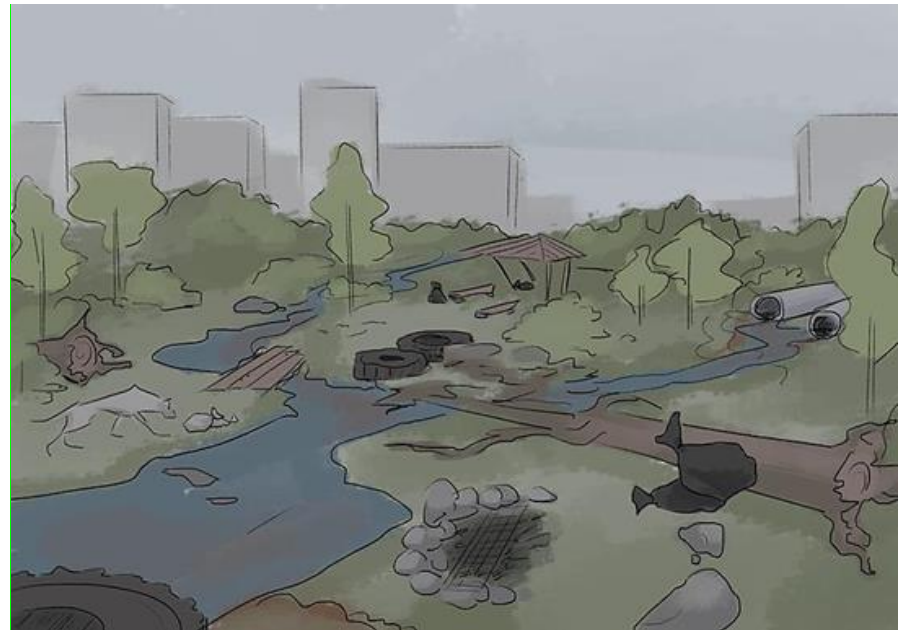

Fig. 4. Sketch of the project solution of an active holiday zone

For this reason it is expedient not to liquidate, but to transform these sites gradually. And it is desirable to keep the possibility of their perception by people as a "wild" image of this territory within their improvement (fig. 5).

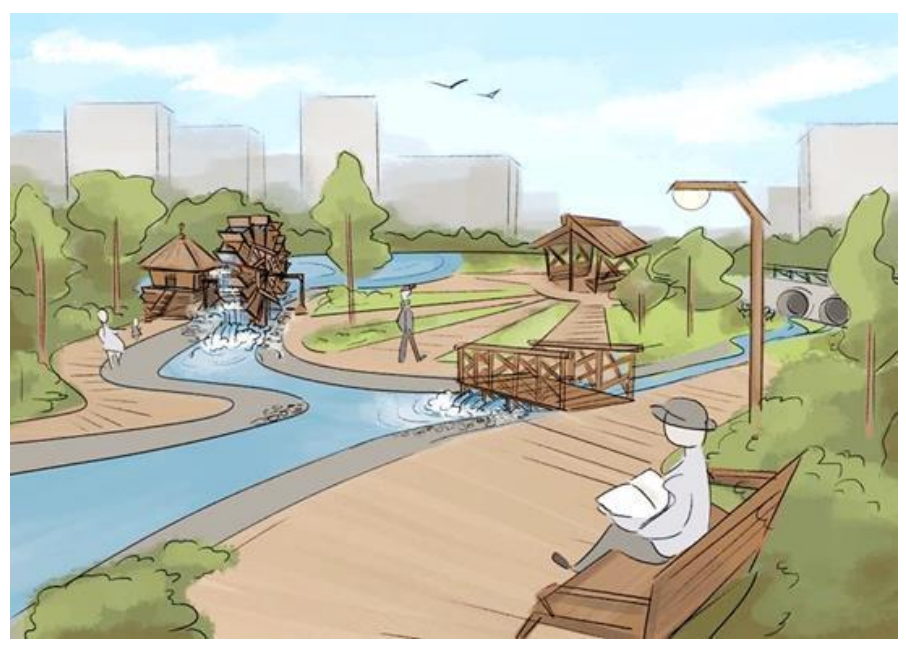

Fig. 5. Sketch of the project solution of an active holiday zone

\section{Conclusion}

1. The remained sites of hydrographic network of the megalopolis can become the basis for the creation of a city resort system. Their visit by inhabitants prevents the development of 
ecological frustrations and deprivations, which are the cause of a complex of dangerous diseases. Thus, the organization of ecologically focused resort on the basis of water objects is a significant factor, ensuring the sustainable development of the cities.

2. The development of various types of resorts has to be of a system and versatile character. In total they have to become the public space, which is rather evenly distributed across the residential territory of the megalopolis.

3. The events for ecological education, held in the resorts have to be organized not only as an educational activity, but also as the means of attraction of city dwellers

\section{References}

1. A. Suzdaleva. Ecology of Urban Areas, 3, 12-17 (2015)

2. V. Filin Videoecology. (MC Videoekologiya, Moscow, 1997)

3. A. Suzdaleva, V. Beznosov. Ecology and development of society, 1, 23-27 (2012)

4. I. Ivashkina, M. Grigoryeva, I. Kharchenko, A. Zakharov, Ecology of Urban Areas, 4, 48-54 (2012)

5. A. Suzdaleva, A. Hirsch, M. Kuchkina, E3S Web of Conf., 157, 02026 (2020).

6. Yu. Fedosyuk, Moscow in the Sadovyh ring. (Publ. Moskovskij rabochij, Moscow, 1983)

7. A. Belyakov, IVS ANTIQVVM, 1, 125-135 (1998).

8. I. Avilova, V. Korbut, S. Fokin, Urbanized population of waterfowl (Anas platyrhynchos) in Moscow. (Publ. MSU, Moscow, 1994)

9. D. Gostishchev, N. Khvatish, D. Valiev, Naucnyj zurnal Rossijskogo NII problem melioracii, 3, 238-250 (2016).

10. R. Solso. Cognitive psychology. (Piter, St. Petersburg, 2006)

11. V. Baybikov, Speleology and Spelestology, 2, 254-261 (2011).

12. A. Suzdaleva, V. Kurochkina, M. Kuchkina, B. Jargalsaihan, E3S Web Conf., 217, 02003 (2020)

13. A. Suzdaleva, V. Beznosov, A. Suzdaleva, Ecology of Urban Areas, 3, 29-34 (2012). 